\title{
Predictive factors of outcome of selective retina therapy for diabetic macular edema
}

\author{
Manabu Yamamoto, Yoko Miura, Kumiko Hirayama, Takeya \\ Kohno, Daijiro Kabata, Dirk Theisen-Kunde, Ralf Brinkmann, \\ Shigeru Honda
}

\begin{tabular}{|c|l|}
\hline Citation & International Ophthalmology. 40(5); 1221-1232 \\
\hline Published & $2020-01-16$ \\
\hline Issue Date & $2020-05$ \\
\hline Type & Journal Article \\
\hline Textversion & Author \\
\hline Rights & $\begin{array}{l}\text { This is a post-peer-review, pre-copyedit version of an article published in } \\
\text { International Ophthalmology. The final authenticated version is available online } \\
\text { at: https://doi.org/10.1007/s10792-020-01288-6. } \\
\text { See Springer Nature terms of use : } \\
\text { https://www.springer.com/gp/open-access/publication-policies/aam-terms-of-use }\end{array}$ \\
\hline DOI & \begin{tabular}{c}
$10.1007 /$ s10792-020-01288-6 \\
\hline
\end{tabular} \\
\hline
\end{tabular}

\author{
Self-Archiving by Author(s) \\ Placed on: Osaka City University
}

Yamamoto, M., Miura, Y., Hirayama, K. et al. Predictive factors of outcome of selective retina therapy for diabetic macular edema. International Ophthalmology. 40, 1221-1232 (2020). doi:0.1007/s10792-020-01288-6 
$\underline{\text { Title }}$

Predictive factors of outcome of selective retina therapy for diabetic macular edema.

\section{Running Title}

Predictive factors of SRT for DME

\section{Authors}

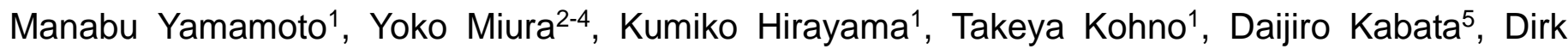
Theisen-Kunde², Ralf Brinkmann"2,3, Shigeru Honda ${ }^{1}$

\section{Affiliation}

1: Department of Ophthalmology and Visual Science, Osaka City University Graduate School of Medicine, 2: Medical Laser Center Luebeck, 3. Institute of Biomedical Optics, University of Luebeck, 4: Department of Ophthalmology, University of Luebeck, 5: Department of Medical Statistics, Osaka City University Graduate School of Medicine.

\section{Corresponding author}

Manabu Yamamoto, M.D., Ph.D., Department of Ophthalmology and Visual Sciences, Osaka City University Graduate School of Medicine, 1-4-3 Asahi-machi, Abeno-ku, 545-8585, Osaka, Japan; Phone: +81-66645-3867; FAX: +81-6634-3873; e-mail: shidai.srtmaia@gmail.com 


\section{$\underline{\text { Abstract }}$}

Purpose: To investigate the predictive factors of clinical outcome of Selective Retina Therapy (SRT) for diabetic macular edema (DME).

Methods: This retrospective study included 22 eyes of 22 patients (15 males and 7 females), who were treated with SRT for DME at the department of Ophthalmology of Osaka City University Hospital, and observed at least 6 months after the treatment. The mean age was 64 years (range 40-81). 13 of the 22 eyes (59\%) had a treatment history other than SRT before. SRT laser (527 nm, $1.7 \mu \mathrm{s}, 100 \mathrm{~Hz}$ ) was used for treatment. Changes of the best corrected visual acuity (BCVA) (logMAR) and central macular thickness (CMT) in optical coherence tomography (OCT) were examined at baseline, 3-month follow-up, and 6-month follow-up. Factors associated with the rate of change in CMT at 3 and 6 months after SRT were examined.

Results: The mean BCVA (logMAR) were $0.26 \pm 0.31,0.22 \pm 0.27$ and $0.23 \pm 0.29$ at baseline, 3 months and 6 months, respectively ( $P=0.15$ at 3 months, 0.40 at 6 months; compared to baseline). The mean CMT were 502 $\pm 163,493 \pm 204$ and $416 \pm 185 \mu \mathrm{m}$ at baseline, 3 months and 6 months, respectively ( $\mathrm{P}=0.69$ at 3 months, 0.01 at 6 months; compared to baseline). The multivariate analysis found a significant negative association with previous macular photocoagulation $(p=0.03)$ at 3 months, and positive association with history of insulin use $(p=0.02)$ and previous panretinal photocoagulation $(p=0.03)$ at 6 months after SRT.

Conclusion: The CMT was significantly decreased at 6 months after SRT in DME. A history of insulin use and panretinal photocoagulation may positively, a history of macular photocoagulation may negatively affect the outcome of SRT, which must be considered when determining the therapeutic indications for SRT.

Keywords: macular edema, diabetic retinopathy, laser therapy, Retinal pigment epithelium 


\section{Introduction}

Diabetic macular edema (DME) is an ocular complication of diabetes, and is one of the critical conditions that may cause serious visual impairment [1,2]. Factors that contribute to the development of DME include elevated vascular permeability, impaired perfusion due to vascular occlusion, retinal pigment epithelium (RPE) damage, and traction by the posterior vitreous membrane.

Treatments for DME have included retinal photocoagulation, vitreous surgery, and sub-tenon triamcinolone injection [3-9]. Although laser photocoagulation was previously considered as a gold standard of DME treatment, intravitreal injections of anti-vascular endothelial growth factor (anti-VEGF) have proven to be more effective than grid macular coagulations in maintaining visual function and are now regarded as the first-choice treatment for DME [10-13]. However, the half-life of anti-VEGF agents in the vitreous body is $2.9-3.9$ days $[14,15]$, and the therapeutic effect demonstrated in clinical trials lasts only 1-2 months per treatment, and thus administration must be frequently repeated.

Selective retinal therapy (SRT) was developed as a laser procedure in which the RPE is selectively damaged without affecting the neural retina and choroid [16-18]. In this procedure, a microsecond $(1.7 \mu \mathrm{s})$ pulsed laser is used to induce an instantaneous temperature rise at just the melanosomes within RPE cells, which leads to the formation of microbubbles around these melanosomes. Their temporary expansion results in a cell volume expansion and eventually mechanical cellular disruption without an increase of temperature in the surrounding tissue. In recent SRT systems, an optoacoustic technique is integrated to enable irradiations with pulse energies close above bubble formation threshold (lit). In the previous studies, SRT has been reported to be effective for CSCR and DME, etc [18-22].

The accumulation of extracellular fluid observed in DME is caused by the breakdown of the inner and outer blood-retinal barriers, which can be affected by systemic conditions including diabetes and hypertension [2]. Clinical outcome of DME treatment may also be influenced by various clinical and pathological factors, such as previous treatments and morphological features. Therefore, in 
this study, we carried out a retrospective investigation to evaluate the factors which may affect the therapeutic effectiveness of SRT on DME at 3 and 6 months after the treatment.

\section{Materials and Methods}

\section{Subjects}

This study was approved by the ethics committee of our hospital, carried out on the basis of the Declaration of Helsinki, and registered with University hospital Medical Information Network (UMIN) (No. 000010471). Written informed consent was obtained from all patients prior to enrolment. This study investigated 22 eyes in 22 DME patients (15 eyes of 15 men and 7 eyes of 7 women), who underwent SRT in the Department of Ophthalmology at Osaka City University Hospital between March 2013 and March 2017 and were followed-up for at least 6 months. The mean age of patients was 64.2 years (range, $40-81$ years). Table 1 shows baseline characteristics of the patients. 13 of these 19 eyes (59\%) had undergone treatment before SRT, consisting of macular photocoagulation in 8 eyes (36\%), panretinal photocoagulation (PRP) in 13 eyes (59\%), sub-Tenon triamcinolone injection (STTA) in 4 eyes (18\%), anti-VEGF therapy in 7 eyes (32\%), and vitreous surgery in 13 eyes (59\%). Diabetic retinopathy was classified as mild nonproliferative retinopathy in 5 eyes (23\%), moderate or severe preproliferative retinopathy in 3 eyes (14\%), and proliferative retinopathy in 13 eyes (59\%). Previous antihypertensive treatment, history of smoking, duration of diabetes, and history of insulin use were ascertained from medical questionnaires. There was no change in treatment for diabetes during study period for all patients.

\section{Inclusion and exclusion criteria}

The inclusion criterion for SRT was clinically significant macular edema according to ETDRS criteria giving rise to subjective symptoms such as central scotoma, metamorphopsia, and reduced visual acuity [3]. Patients with a central macular thickness (CMT) $>250 \mu \mathrm{m}$ measured by optic coherence tomography (OCT) were included.

Ophthalmological exclusion criteria were: 
1) loss of sight in one eye;

2) optic media that is insufficiently transparent to acquire fundus images or obtain other imaging findings from the eye to be treated;

3) presence of inflammatory intraocular disorders, including infectious disorders;

4) intraocular surgery or laser treatment within 6 months;

5) intravitreal injection within 3 months;

6) presence of comorbidity reducing visual acuity of the eye to be treated or that may require medical or surgical treatment during the study period;

7) ophthalmic impairment in the eye to be treated that would confuse interpretation of the effectiveness of treatment in the judgement of an investigator or subinvestigator;

8) scarring or atrophy of the central fovea indicating that reduced visual acuity of the eye to be treated would not be recoverable;

9) vitreous traction or epiretinal membrane in the eye to be treated visible on biological optical microscopy or OCT that would significantly affect central visual acuity in the judgement of an investigator or subinvestigator;

10) neovascularization of the iris or vitreous haemorrhage in the eye to be treated;

11) signs of infectious blepharitis, keratitis, scleritis, or conjunctivitis in the eye to be treated, or currently undergoing treatment for serious systemic infectious disease.

Systemic exclusion criteria were:

1) systemic inflammatory disease;

2) haemorrhagic diathesis, or other condition of currently undergoing anticoagulant therapy judged to entail a high risk of serious haemorrhage during treatment;

3) pregnancy or the possibility of pregnancy;

4) a history of untreated or poorly controlled hypertension, diabetes, or other systemic disease judged to have a significant effect on treatment;

5) a systemic condition judged as rendering it impossible to attend hospital for continued treatment. 


\section{Clinical observations}

All patients underwent the following ophthalmic observations at baseline and at 3 and 6 months after the treatment: the best corrected visual acuity (BCVA) measurement, slit-lamp microscopy, funduscopy, OCT(SPECTRALIS ${ }^{\circledR}$; Heidelberg Engineering GmbH, Heidelberg, Germany), color fundus photography, fundus autofluorescence, and fluorescein angiography (FA) (SPECTRALIS ${ }^{\circledR}$ ). For the BCVA analysis, decimal visual acuities were converted to logarithmic minimum angle of resolution (logMAR) values.

\section{SRT method}

The SRT laser used in this study was a Q-switched frequency-doubled neodymium-doped yttrium lithium fluoride laser (Nd:YLF) operating at a wavelength of $527 \mathrm{~nm}$ (Medical Laser Center Lübeck, Lübeck, Germany). The pulse duration was $1.7 \mu \mathrm{s}$, and 30 pulses per irradiation site were applied with a repetition rate of $100 \mathrm{~Hz}$. A 1.05× magnification Mainster central field contact lens was used, and the slit lamp optics was adjusted such that the irradiation diameter on the retina was approximately $200 \mu \mathrm{m}[20]$.

The extent of irradiation was determined by identifying the location of the macular edema before SRT using FA and OCT. The area of the edema was covered in a grid pattern, with the spacing between spots of about one spot diameter $(200 \mu \mathrm{m})$ and sparing the central $500-\mu \mathrm{m}$ area. Because the irradiated locations are ophthalmoscopically invisible, microbubble generation within the RPE and resulting cell destruction were estimated from the optoacoustic (OA) value, as described in a previous report [22]. The OA value is a number which is calculated from the ultrasonic waves generated during microbubble formation leading to cell disintegration. The pressure waves are recorded by an ultrasonic transducer embedded in the contact lens. According to the study, the OA value indicating $50 \%$ probability of RPE cell disruption (Effective Dose (ED) 50 ) is 70, and the one indicating $90 \%$ probability (ED90) is 112 as a result of calculating the leakage as positive on FA in the used system. 


\section{Outcome measures}

Visual acuity, OCT, and FA were performed before treatment and 3 and 6 months later, as well as changes in BCVA. Central macular thickness (CMT) and fluorescein leakage during FA were also investigated. With regard to BCVA, changes of $\log M A R \geq 0.2$ were considered significant. A change in CMT $\geq 15 \%$ compared with the pre-treatment baseline was regarded as significant as previously described [23]. SRT was considered effective if CMT decreased significantly compared to baseline, and as ineffective if this was not the case. As factors that might influence the rate of change in CMT 3 and 6 months after SRT, we evaluated sex, age ( $\geq 65$ years vs. $<65$ years), previous hypertension, smoking history, history of diabetes, history of insulin use, previous cataract surgery (crystalline lens/intraocular lens), stage of diabetic retinopathy (proliferative vs. nonproliferative), previous treatment (macular photocoagulation, panretinal photocoagulation, anti-VEGF therapy, or vitreous surgery), baseline BCVA, baseline CMT, type of DME (diffuse vs. other), ellipsoid zone (EZ) abnormality, and foveal avascular zone (FAZ) abnormality. The type of DME was classified into focal and diffuse based on the leakage using FA following previous reports [24]. EZ abnormality was evaluated within $500 \mu \mathrm{m}$ of the central fovea in the horizontal plane on OCT, and then graded as follows: 0 , normal (no disruption of $E Z$ ); 1, abnormal (some disruption of $E Z$ ); or 2, absent (EZ not visible). FAZ abnormality was graded as 0-4 using FA in accordance with the Early Treatment Diabetic Retinopathy Study (ETDRS) charts [21].

\section{Statistical analysis}

Changes in BCVA (logMAR) and CMT from baseline were assessed using a paired t-test. With respect to the association between the effectiveness of SRT and the various parameters, univariate analyses were performed.

In order to assess the associations between the changes of CMT after SRT treatment and clinical factors among SRT treated patients, we performed a univariable linear regression analyses with the change value of CMT at 6 months as the function of each clinical characteristic. Furthermore, the multivariable linear regression models were utilized with adjustment for baseline CMT value to 
reduce the effect of confounding by baseline CMT (the association between the change of CMT and baseline CMT was examined with adjustment for stage of DR). Similar regression analyzes were conducted with the 3 months CMT change values as the dependent variable.

These analyses were performed with 2 -sided $5 \%$ significance level using $R$ version 3.6.0 (https://cran.r-project.org/) and IBM ${ }^{\circledR}$ SPSS ${ }^{\circledR}$ Statistics 24.0 (IBM Japan, Ltd., Tokyo, Japan).

\section{$\underline{\text { Results }}$}

Figure 1 and 2 shows a typical case of DME treated with SRT. The mean number of irradiations in one SRT was $47.4 \pm 17.4$ (range, 25-86). Per patient, the mean number of irradiations with <ED50 $(\mathrm{OA}<70)$ was $7.6 \pm 7.0(15.8 \% \pm 14.9 \%)$, the mean number of irradiations with $\geq$ ED50 but $<$ ED90 $(70 \leq \mathrm{OA}<112)$ was $15.0 \pm 12.0(26.4 \% \pm 17.3 \%)$, and the mean number of irradiations with $\geq$ ED90 $(\mathrm{OA} \geq 112)$ was $24.3 \pm 11.7(57.8 \% \pm 22.2 \%)$ (Figure 3$)$.

Mean BCVA ( $\log M A R)$ was $0.26 \pm 0.31$ before SRT, $0.22 \pm 0.27$ after 3 months, and $0.23 \pm 0.29$ after 6 months, with no significant difference ( 3 months, $p=0.15$; 6 months, $p=0.40$ ) (Figure 4a). Individually, after 3 months BCVA had improved in $9 \%$ of patients and was unchanged in $91 \%$, and after 6 months had improved in 18\%, was unchanged in 77\%, and had worsened in 5\% (Figure 5a). Mean CMT was $502 \pm 163 \mu \mathrm{m}$ before SRT, $493 \pm 204 \mu \mathrm{m}$ after 3 months, and $416 \pm 185 \mu \mathrm{m}$ after 6 months, showing a significant decrease after 6 months ( 3 months, $p=0.69 ; 6$ months, $p=0.01$ ) (Figure 4b). Individually, after 3 months CMT had decreased in 14\% of patients, was unchanged in $68 \%$, and had increased in $18 \%$, and after 6 months had decreased in $50 \%$, was unchanged in $45 \%$, and had increased in $5 \%$ (Figure $5 b$ ).

Comparison of the leakage in FA showed that, 3 months after SRT, leakage was decreased in 27\% and unchanged in $73 \%$ of cases compared to the baseline; at 6 months after SRT, leakage was decreased in $27 \%$, unchanged in $68 \%$ and increased in $5 \%$ of cases (Figure $5 \mathrm{c}$ ).

The Table 2 and 3 shows univariate and multivariate analysis of factors associated with the rate of change in CMT at 3 and 6 months after SRT. The multivariate analysis found a significant negative 
association with previous macular photocoagulation $(p=0.03$, odds ratio $0.064,95 \%$ confidence interval $0.005-0.816)$ at 3 months, and positive association with history of insulin use $(p=0.02$, odds ratio $-6.65,95 \%$ confidence interval $-11.84--1.46$ ) and previous panretinal photocoagulation $(p=0.03$, odds ratio $-7.03,95 \%$ confidence interval $-13.32--0.75)$ at 6 months after SRT.

During this study, no patient developed cerebral infarction, myocardial infarction, or other systemic disease, or intraocular inflammation, haemorrhage, or other event attributable to laser irradiation.

\section{Discussion}

DME is a chronic condition that persists or recurs in many patients, and repeated treatments are often required for a long time. In fact, 13 of the 22 eyes in our study had previously undergone other treatment for DME. Anti-VEGF therapy is presently the first line treatment for DME, which shows a prompt and remarkable effect, hence SRT is not the first-choice therapy for DME patients. However, the reduction of DME after a single SRT was evident 6 months after the treatment, which suggests that the effect of SRT can be maintained for a long-term in the patients who respond to the treatment.

This study found that the mean CMT in DME patients was significantly decreased 6 months after SRT with an overall improvement rate of $50 \%$. Given that $59 \%$ of our cases (13 of the 22 eyes) had previously undergone treatment with anti-VEGF therapy or vitrectomy, this indicates that SRT may induce reduction of macular edema for both naïve and treated cases. Previous studies showed that SRT reduces macular edema in both treatment-naïve and previously treated DME $[18,19]$. Our findings are consistent with those results.

A significant negative association was found with previous macular photocoagulation at 3 months after SRT, but no association was found at 6 months. This can be interpreted such that previous macular photocoagulation may delay the effect of SRT leading to resolution of edema. Different from conventional photocoagulation, SRT laser generates microbubbles within the RPE, breaking down the RPE cells alone without damaging photoreceptor cells [25-27], which could be indirectly confirmed with the measured OA values as presented. One possible mechanism for the reduction 
of edema is an acceleration of a drainage function of submacular RPE by the reconstructed monolayer structure through the proliferation of RPE cells. Conventional macular photocoagulation for DME causes degeneration of the RPE and retinal tissues by thermal denaturation, which may cause scarring of the retina. Hens the potential of RPE wound healing, consisted mainly of migration and proliferation of cells, in the retina undergone macular grid photocoagulation might be different from the monolayer without scar formation and it might cause the delay of functional reepithelialization after treatment. Our investigation also identified history of insulin use and previous PRP associated with the reduction of CMT at 6 months after SRT. Insulin use may generally reduce the level of blood glucose, thus can be consequently associated with $\mathrm{HbA1c}$. However, $\mathrm{HbA} 1 \mathrm{c}$ did not show significant association with the reduction of CMT, thus blood glucose level or stability does not seem to be the main explanation of this high association between insulin use and CMT reduction. On the other hand, Insulin has been reported to stimulate wound healing of different cell/tissue types through activation of different kinase pathways responsible to cell migration and proliferation [28]. For RPE cells, too, insulin showed a weak to moderate stimulatory effect on proliferation of human RPE cells if applied alone [29]. This could be a possible mechanism of the positive association between insulin use and CMT reduction after SRT, in which RPE wound healing is one of the initial key therapeutic processes.

PRP is performed generally for the proliferative or severe pre-proliferative DR, in order to improve retinal oxygenation [30]. Therefore, the obtained statistic result could be interpreted that SRT might reduce macular edema more effectively in the retina with better intraretinal oxygen supply. Although association between the extent of retinal oxygenation and the response of RPE cells to laser irradiation in diabetic patients has not been well investigated yet to date, hyperbaric oxygen has shown positive therapeutic effects in the process of wound healing in the foot ulcer of diabetic patients [31].

Patients who have undergone vitreous surgery exhibit increased clearance of anti-VEGF therapy and the multiple injections of anti-VEGF agents have also been reported to increase the incidence 
of endophthalmitis and other ocular complications [32, 33]. In the patients with a history of vascular infarction-related disease, the anti-VEGF therapy may also increase the risk of cerebral or myocardial infarction. Particularly in diabetic patients, the risk of infarction-related disease increases with the progression of diabetes, and the continuous usage of anti-VEGF agents for long-term must be performed with caution [34, 35]. Since no systemic effects of SRT has been reported to date, this treatment may have an advantage over anti-VEGF therapy for systemic safety.

Although anti-VEGF therapy is highly effective in reducing macular edema, about a half of patients show no improvement in visual function [36]. This may be because DME is a multifactorial disorder that is not caused by VEGF alone. The main effect of anti-VEGF therapy is to regulate an excess permeability of the retinal vessels and reducing leakage into the neuronal retina [37]. The therapeutic mechanism of SRT is considered, as described above, to lie primarily on the restored RPE function including drainage function [18, 19]. SRT thus may improve macular edema via a different mechanism from those of other treatment modalities, and it suggests that SRT may be a useful alternative or concomitant treatment of other treatment modalities with different therapeutic mechanisms, especially because SRT is free of any adverse effect.

Recently, other different types of minimally-invasive retinal laser treatment procedures, such as subthreshold micropulse laser (SML) treatment, were also reported to be effective in treating eyes with DME [38-40]. It might be thus also interesting to elucidate in future studies the differences in clinical results and determining factors among these different interventions. However, so far SRT is the only sub-visible treatment modality with an individual and accurate spot-by-spot dosing control. In conclusion, SRT is one of the treatment modalities to reduce DME over 6 months of follow-up. SRT may be affected by history of insulin use and photocoagulation, and our results suggested that this must be taken into consideration when determining the indications for SRT. This study was limited by the inclusion of only a small number of patients and by a non-randomized study design. Further prospective studies with a larger number of patients will be useful to confirm the factors associated with the outcomes of SRT. 


\section{Acknowledgments}

None.

\section{Compliance with ethical standards}

\section{Conflict of interest}

The authors declare that they have no conflict of interest.

\section{Ethical approval}

This study was approved by the ethics committee of our hospital, carried out on the basis of the

Declaration of Helsinki, and registered with University hospital Medical Information Network (UMIN) (No. 000010471).

\section{Informed consent}

Written informed consent was obtained from all patients prior to enrolment. 


\section{$\underline{\text { References }}$}

1. Cheung N, Mitchell P, Wong TY (2010) Diabetic retinopathy. Lancet 376:124-36

2. Tan GS, Cheung N, Simo R, Cheung GC, Wong TY (2017) Diabetic macular oedema. Lancet Diabetes Endocrinol 5:143-55

3. Early Treatment Diabetic Retinopathy Study Research Group (1985) Photocoagulation for diabetic macular edema. ETDRS report number 1. Arch Ophthalmol 103:1796-806

4. Patelli F, Fasolino G, Radice P, Russo S, Zumbo G, DI Tizio FM, Frisone G, Marchi S (2005) Time course of changes in retinal thickness and visual acuity after intravitreal triamcinolone acetonide for diffuse diabetic macular edema with and without previous macular laser treatment. Retina 25:840-5

5. Beck RW, Edwards AR, Aiello LP, Bressler NM, Ferris F, Glassman AR, Hartnett E, Ip MS, Kim JE, Kollman C (2009) Three-year follow-up of a randomized trial comparing focal/grid photocoagulation and intravitreal triamcinolone for diabetic macular edema. Arch Ophthalmol $127: 245-51$

6. Scott IU, Ip MS, VanVeldhuisen PC, Oden NL, Blodi BA, Fisher M, Chan CK, Gonzalez VH, Singerman LJ, Tolentino M (2009) A randomized trial comparing the efficacy and safety of intravitreal triamcinolone with standard care to treat vision loss associated with macular edema secondary to branch retinal vein occlusion: the Standard Care vs Corticosteroid for Retinal Vein Occlusion (SCORE) study report 6. Arch Ophthalmol 127:1115-28

7. Laidlaw DA (2008) Vitrectomy for diabetic macular oedema. Eye (Lond) 22:1337-41

8. Diabetic Retinopathy Clinical Research Network Writing Committee (2010) Vitrectomy outcomes in eyes with diabetic macular edema and vitreomacular traction. Ophthalmology $117: 1087-93$

9. Simunovic MP, Hunyor AP, Ho IV (2014) Vitrectomy for diabetic macular edema: a systematic review and meta-analysis. Can J Ophthalmol 49:188-95

10. Wells JA, Glassman AR, Ayala AR, Jampol LM, Bressler NM, Bressler SB, Brucker AJ, Ferris 
FL, Hampton GR, Jhaveri C, Melia M, Beck RW (2016) Aflibercept, bevacizumab, or ranibizumab for diabetic macular edema: two-year results from a comparative effectiveness randomized clinical trial. Ophthalmology 123:1351-9

11. Brown DM, Nguyen QD, Marcus DM, Boyer DS, Patel S, Feiner L, Schlottmann PG, Rundle AC, Zhang J, Rubio RG, Adamis AP, Ehrlich JS, Hopkins J (2013) Long-term outcomes of ranibizumab therapy for diabetic macular edema: the 36-month results from two phase III trials: RISE and RIDE. Ophthalmology 120:2013-22

12. Diabetic Retinopathy Clinical Research Network (2015) Aflibercept, bevacizumab, or ranibizumab for diabetic macular edema. N Engl J Med 372:1193-203

13. Elman MJ, Ayala A, Bressler NM, Browning D, Flaxel CJ, Glassman AR, Jampol LM, Stone TW (2015) Intravitreal ranibizumab for diabetic macular edema with prompt versus deferred laser treatment: 5-year randomized trial results. Ophthalmology 122:375-81

14. Bakri SJ, Snyder MR, Reid JM, Pulido JS, Ezzat MK, Singh RJ (2007) Pharmacokinetics of intravitreal ranibizumab (Lucentis). Ophthalmology. 114:2179-82

15. Park SJ, Choi Y, Na YM, Hong HK, Park JY, Park KH, Chung JY, Woo SJ (2016) Intraocular Pharmacokinetics of Intravitreal Aflibercept (Eylea) in a Rabbit Model. Invest Ophthalmol Vis Sci. 57:2612-7

16. Roider J, Brinkmann R, Wirbelauer C, Laqua H, Birngruber R (1999) Retinal sparing by selective retinal pigment epithelial photocoagulation. Arch Ophthalmol 117:1028-34

17. Brinkmann R, Roider J, Birngruber R (2006) Selective retina therapy (SRT): a review on methods, techniques, preclinical and first clinical results. Bull Soc Belge Ophtalmol 302:51-69

18. Roider J, Liew SH, Klatt C, Elsner H, Poerksen E, Hillenkamp J, Brinkmann R,Birngruber, R (2010) Selective retina therapy (SRT) for clinically significant diabetic macular edema. Graefes Arch Clin Exp Ophthalmol 248:1263-72

19. Park YG, Kim JR, Kang S, Seifert E, Theisen-Kunde D, Brinkmann R, Roh YJ (2016) Safety and efficacy of selective retina therapy (SRT) for the treatment of diabetic macular edema in Korean patients. Graefes Arch Clin Exp Ophthalmol 254:1703-13 
20. Elsner H, Pörksen E, Klatt C, Bunse A, Theisen-Kunde D, Brinkmann R, Birngruber R, Laqua H, Roider J (2006) Selective retina therapy in patients with central serous chorioretinopathy. Graefes Arch Clin Exp Ophthalmol. 244:1638-45

21. Klatt C, Saeger M, Oppermann T, Pörksen E, Treumer F, Hillenkamp J, Fritzer E, Brinkmann R, Birngruber R, Roider J (2011) Selective retina therapy for acute central serous chorioretinopathy. Br J Ophthalmol 95:83-8

22. Yasui A, Yamamoto M, Hirayama K, Shiraki K, Theisen-Kunde D, Brinkmann R, Miura Y, Kohno T (2017) Retinal sensitivity after selective retina therapy (SRT) on patients with central serous chorioretinopathy. Graefes Arch Clin Exp Ophthalmol 255:243-54

23. Klein KA, Cleary TS, Reichel E (2017) Effect of intravitreal aflibercept on recalcitrant diabetic macular edema. Int J Retina Vitreous 3:16

24. Kang SW, Park CY, Ham DI (2004) The correlation between fluorescein angiographic and optical coherence tomographic features in clinically significant diabetic macular edema. Am J Ophthalmol. 137:313-22

25. Roider J, Hillenkamp F, Flotte T, Birngruber R (1993) Microphotocoagulation: selective effects of repetitive short laser pulses. Proc Natl Acad Sci U S A 90:8643-7

26. Roider J, Brinkmann R, Wirbelauer C, Laqua H, Birngruber R (2000) Subthreshold (retinal pigment epithelium) photocoagulation in macular diseases: a pilot study. $\mathrm{Br} \mathrm{J}$ Ophthalmol 84:40-7

27. Framme C, Walter A, Prahs P, Theisen-Kunde D, Brinkmann R (2008) Comparison of threshold irradiances and online dosimetry for selective retina treatment (SRT) in patients treated with 200 nanoseconds and 1.7 microseconds laser pulses. Lasers Surg Med 40:616-24

28. AbdelKader DH, Osman MA, Elgizawy SA, Faheem AM McCarron PA (2016) The Role of Insulin in Wound Healing Process: Mechanism of Action and Pharmaceutical Applications" Mechanism of Action and Pharmaceutical Applications. J Anal Pharm Res 2:00007

29. Leschey KH, Hackett SF, Singer JH, Campochiaro PA (1990) Growth factor responsiveness of human retinal pigment epithelial cells. Invest Ophthalmol Vis Sci 31: 839-46 
30. Stefánsson E, Machemer R, de Juan E Jr, McCuen BW 2nd, Peterson J (1992) Retinal oxygenation and laser treatment in patients with diabetic retinopathy. Am J Ophthalmol 15: 36-8.

31. Tejada S, Batle JM, Ferrer MD, Busquets-Cortés C, Monserrat-Mesquida M, Nabavi SM, Del Mar Bibiloni M, Pons A, Sureda A (2019) Therapeutic Effects of Hyperbaric Oxygen in the Process of Wound Healing. Curr Pharm Des 25: 1682-1693

32. Lee SS, Ghosn C, Yu Z, Zacharias LC, Kao H, Lanni C, Abdelfattah N, Kuppermann B, Csaky KG, D'Argenio DZ, Burke JA, Hughes PM, Robinson MR (2010) Vitreous VEGF clearance is increased after vitrectomy. Invest Ophthalmol Vis Sci 51:2135-8

33. Falavarjani KG, Nguyen QD (2013) Adverse events and complications associated with intravitreal injection of anti-VEGF agents a review of literature. Eye (Lond) 27:787-94

34. Tolentino M (2011) Systemic and ocular safety of intravitreal anti-VEGF therapies for ocular neovascular disease. Surv Ophthalmol 56:95-113

35. Nguyen-Khoa BA, Goehring EL, Werther W, Fung AE, Do DV, Apte RS, Jones JK (2012) Hospitalized cardiovascular events in patients with diabetic macular edema. BMC Ophthalmol $12: 11$

36. Sim DA, Keane PA, Tufail A, Egan CA, Aiello LP, Silva PS (2015) Automated retinal image analysis for diabetic retinopathy in telemedicine. Curr Diab Rep 15:14

37. Simo R, Sundstrom JM, Antonetti DA (2014) Ocular anti-VEGF therapy for diabetic retinopathy: the role of VEGF in the pathogenesis of diabetic retinopathy. Diabetes Care 37:893-9

38. Ohkoshi, K, Yamaguchi, T (2010) Subthreshold Micropulse Diode Laser Photocoagulation for Diabetic Macular Edema in Japanese Patients. Am J Ophthalmol 149:133-9

39. Luttrull JK, Dorin G (2012) Subthreshold diode micropulse laser photocoagulation (SDM) as invisible retinal phototherapy for diabetic macular edema: a review. Curr Diabetes Rev 8:274-84

40. Inagaki K, Ohkoshi K, Ohde S, Deshpande GA, Ebihara N, Murakami A (2015) Comparative efficacy of pure yellow (577-nm) and 810-nm subthreshold micropulse laser photocoagulation 
combined with yellow (561-577-nm) direct photocoagulation for diabetic macular edema. Jpn J Ophthalmol 59:21-8 


\section{Tables}

Table 1 Patient characteristics at baseline

\begin{tabular}{|c|c|c|}
\hline \multicolumn{3}{|l|}{ Characteristics } \\
\hline Number & \multicolumn{2}{|c|}{22 Cases (22 eyes) } \\
\hline Sex & \multicolumn{2}{|c|}{ Male 15, Female 7} \\
\hline Age; Mean (Range) & \multicolumn{2}{|c|}{$64.2(40-81)$} \\
\hline Hypertension (\%) & \multicolumn{2}{|c|}{$13(59)$} \\
\hline Smoking (\%) & \multicolumn{2}{|c|}{$13(59)$} \\
\hline Duration of diabetes; Median, (Range) & \multicolumn{2}{|c|}{$10(3-30)$} \\
\hline HbA1c; Median (Range) & \multicolumn{2}{|c|}{$6.9 \%(5.8-9.0)$} \\
\hline Insulin use (\%) & \multicolumn{2}{|c|}{$10(45)$} \\
\hline Intraocular lens (\%) & \multicolumn{2}{|c|}{$12(54)$} \\
\hline Proliferative diabetic retinopathy (\%) & \multicolumn{2}{|c|}{$14(64)$} \\
\hline Macular photocoagulation (\%) & \multicolumn{2}{|c|}{$8(36)$} \\
\hline Previous PRP (\%) & \multicolumn{2}{|c|}{$13(59)$} \\
\hline STTA (\%) & \multicolumn{2}{|c|}{$4(18)$} \\
\hline Anti-VEGF therapy (\%) & \multicolumn{2}{|c|}{7 (32) } \\
\hline Vitreous surgery $(\%)$ & \multicolumn{2}{|c|}{$13(59)$} \\
\hline BCVA (logMAR); Mean, (Range) & \multicolumn{2}{|c|}{$0.26(0.82--0.18)$} \\
\hline CMT: Mean, (Range) & \multicolumn{2}{|c|}{$502 \mu \mathrm{m}(241-776)$} \\
\hline \multirow{2}{*}{ Type of macula edema (\%) } & focal & $11(50)$ \\
\hline & diffuse & $11(50)$ \\
\hline \multirow[t]{3}{*}{ Abnormality of ellipsoid zone (\%) } & normal & $9(37)$ \\
\hline & abnormal & $10(42)$ \\
\hline & absent & $3(21)$ \\
\hline \multirow{5}{*}{$\begin{array}{l}\text { Abnormality of foveal avascular zone (FAZ) } \\
\text { (using FA)(\%) }\end{array}$} & grade 0 & $5(11)$ \\
\hline & grade 1 & $5(32)$ \\
\hline & grade 2 & $5(16)$ \\
\hline & grade 3 & $4(32)$ \\
\hline & grade 4 & $3(11)$ \\
\hline
\end{tabular}


Table 2 Univariate analysis of factors associated with the rate of change in CMT

\begin{tabular}{|c|c|c|c|c|c|c|c|c|}
\hline \multirow[b]{3}{*}{ Age } & \multicolumn{4}{|c|}{$3 \mathrm{M}$} & \multicolumn{4}{|c|}{$6 \mathrm{M}$} \\
\hline & \multirow{2}{*}{$\frac{\mathrm{Cl}}{1.10}$} & \multicolumn{2}{|c|}{$95 \% \mathrm{Cl}$} & \multirow{2}{*}{$\begin{array}{c}p \text { Value } \\
0.56\end{array}$} & \multirow{2}{*}{$\begin{array}{c}\mathrm{Cl} \\
2.18\end{array}$} & \multicolumn{2}{|c|}{$95 \% \mathrm{Cl}$} & \multirow{2}{*}{$\begin{array}{c}\mathrm{p} \text { Value } \\
0.27\end{array}$} \\
\hline & & $(-2.73-$ & $4.93)$ & & & $(-1.8-$ & $6.15)$ & \\
\hline Duration of diabetes (Years) & 2.57 & $(-1.76-$ & $6.90)$ & 0.23 & -2.17 & $(-6.83-$ & $2.50)$ & 0.34 \\
\hline $\mathrm{HbA1c}(\%)$ & -0.73 & $(-5.62-$ & $4.16)$ & 0.76 & 3.42 & $(-1.53-$ & $8.38)$ & 0.17 \\
\hline Smoking & 1.95 & $(-3.65-$ & $7.54)$ & 0.48 & 0.66 & $(-5.35-$ & $6.67)$ & 0.82 \\
\hline History of Insulin use & 0.70 & $(-4.89-$ & $6.29)$ & 0.80 & -6.60 & $(-11.68-$ & $-1.52)$ & 0.01 \\
\hline \multicolumn{9}{|l|}{ Ocular characteristics } \\
\hline Phakia: Intraocular lens & 1.68 & $(-3.86-$ & $7.22)$ & 0.53 & -2.38 & $(-8.22-$ & $3.45)$ & 0.41 \\
\hline Stage of DR (nPDR: PDR) & -0.09 & $(-5.88-$ & $5.70)$ & 0.98 & -3.73 & $(-9.63-$ & $2.17)$ & 0.20 \\
\hline Anti-VEGF therapy & -0.78 & $(-6.75-$ & $5.19)$ & 0.79 & -1.57 & $(-7.88-$ & $4.74)$ & 0.61 \\
\hline Vitrectomy & 2.14 & $(-3.44-$ & $7.72)$ & 0.43 & -2.54 & $(-8.44-$ & $3.36)$ & 0.38 \\
\hline Baseline BCVA (logMAR) & -0.14 & $(-3.42-$ & $3.14)$ & 0.93 & -1.64 & $(-5.04-$ & $1.76)$ & 0.33 \\
\hline Type of macular edema (focal: diffuse) & 4.36 & $(-0.82-$ & $9.55)$ & 0.10 & 2.45 & $(-3.35-$ & $8.26)$ & 0.39 \\
\hline Ellipsoid zone & 3.26 & $(-4.71-$ & $11.24)$ & 0.40 & 3.67 & $(-4.79-$ & $12.12)$ & 0.38 \\
\hline Baseline CMT & -0.50 & $(-4.57-$ & $3.56)$ & 0.80 & -0.92 & $(-5.22-$ & $3.38)$ & 0.66 \\
\hline FAZ grade & -2.26 & $(-1.74-$ & $6.27)$ & 0.25 & -2.18 & $(-6.46-$ & $2.09)$ & 0.30 \\
\hline
\end{tabular}

ClConfidence interval 
Table 3 Multivariate analysis of factors associated with the rate of change in CMT

\begin{tabular}{|c|c|c|c|c|c|c|c|c|}
\hline \multirow[b]{3}{*}{ Age } & \multicolumn{4}{|c|}{$3 \mathrm{M}$} & \multicolumn{4}{|c|}{$6 \mathrm{M}$} \\
\hline & \multirow{2}{*}{$\frac{\mathrm{Cl}}{1.21}$} & \multicolumn{2}{|c|}{$95 \% \mathrm{Cl}$} & \multirow{2}{*}{$\begin{array}{c}\mathrm{p} \text { Value } \\
0.53\end{array}$} & \multirow{2}{*}{$\begin{array}{c}\mathrm{Cl} \\
2.38\end{array}$} & \multicolumn{2}{|c|}{$95 \% \mathrm{Cl}$} & \multirow{2}{*}{$\begin{array}{c}\mathrm{p} \text { Value } \\
0.24\end{array}$} \\
\hline & & $(-2.78-$ & $5.19)$ & & & $(-1.72-$ & $6.49)$ & \\
\hline Duration of diabetes (Years) & 2.56 & $(-1.90-$ & $7.01)$ & 0.24 & -2.19 & $(-6.96-$ & $2.58)$ & 0.35 \\
\hline HbA1c (\%) & -0.73 & $(-5.76-$ & $4.29)$ & 0.76 & 3.41 & $(-1.66-$ & $8.49)$ & 0.18 \\
\hline Smoking & 1.88 & $(-3.97-$ & $7.73)$ & 0.51 & 0.44 & $(-5.82-$ & $6.71)$ & 0.88 \\
\hline History of Insulin use & 0.68 & $(-5.07-$ & $6.42)$ & 0.81 & -6.65 & $(-11.84-$ & $-1.46)$ & 0.02 \\
\hline \multicolumn{9}{|l|}{ Ocular characteristics } \\
\hline Phakia: Intraocular lens & 1.61 & $(-4.29-$ & $7.52)$ & 0.57 & -2.91 & $(-9.05-$ & $3.24)$ & 0.34 \\
\hline Stage of DR (nPDR: PDR) & -0.81 & $(-8.24-$ & $6.62)$ & 0.82 & -7.05 & $(-14.16-$ & $0.06)$ & 0.052 \\
\hline Panretinal photocoagulation & -2.65 & $(-9.27-$ & $3.98)$ & 0.41 & -7.03 & $(-13.32-$ & $-0.75)$ & 0.03 \\
\hline Anti-VEGF therapy & -1.26 & $(-7.90-$ & $5.39)$ & 0.70 & -2.47 & $(-9.43-$ & $4.49)$ & 0.47 \\
\hline Vitrectomy & 2.08 & $(-3.73-$ & $7.88)$ & 0.46 & -2.79 & $(-8.88-$ & $3.30)$ & 0.35 \\
\hline Baseline BCVA (logMAR) & 0.14 & $(-4.00-$ & $4.28)$ & 0.94 & -1.82 & $(-6.11-$ & $2.47)$ & 0.38 \\
\hline Type of macular edema (focal: diffuse) & 4.69 & $(-0.70-$ & $10.09)$ & 0.09 & 2.82 & $(-3.22-$ & $8.86)$ & 0.34 \\
\hline Ellipsoid zone & 3.88 & $(-4.64-$ & $12.40)$ & 0.35 & 4.58 & $(-4.38-$ & $13.55)$ & 0.30 \\
\hline Baseline CMT & -0.84 & $(-6.06-$ & $4.38)$ & 0.74 & -3.89 & ( -8.89 - & $1.10)$ & 0.12 \\
\hline FAZ grade & 2.24 & $(-1.89-$ & $6.37)$ & 0.27 & -2.26 & $(-6.64-$ & $2.12)$ & 0.29 \\
\hline
\end{tabular}

Cl Confidence interval 


\section{Figures}

Fig.1 Example images from a 67-year-old woman with DME treated by SRT who had previously received one vitrectomy, two STTA, five anti-VEGF therapy and PRP.

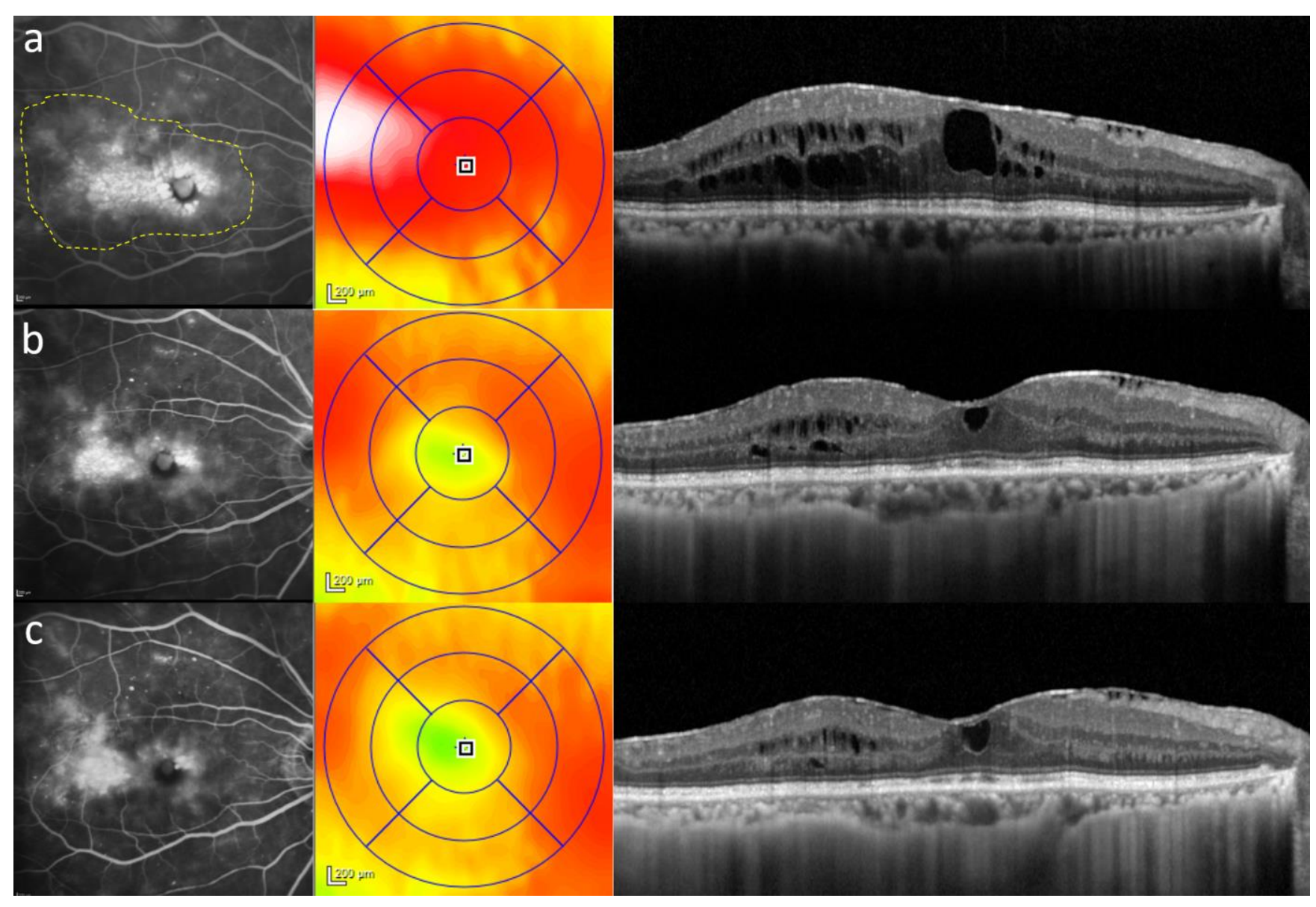

FA (left), retina thickness map of OCT (centre), horizontal line of OCT (right). a) Baseline; b) 3 months after SRT; c) 6 months after SRT. Extent of SRT irradiation (yellow dotted line). Totally 33 spots with energy range from 65 to $106 \mu \mathrm{J}$ were irradiated. CMT was $436 \mu \mathrm{m}$ at baseline, decreasing to $308 \mu \mathrm{m}$ at 3 months follow-up and $309 \mu \mathrm{m}$ at 6 months follow-up of SRT. 
Fig.2 Example images from a 62-year-old man with DME treated by SRT who had previously received one vitrectomy, three STTA, one macular photocoagulation using grid pattern and PRP.

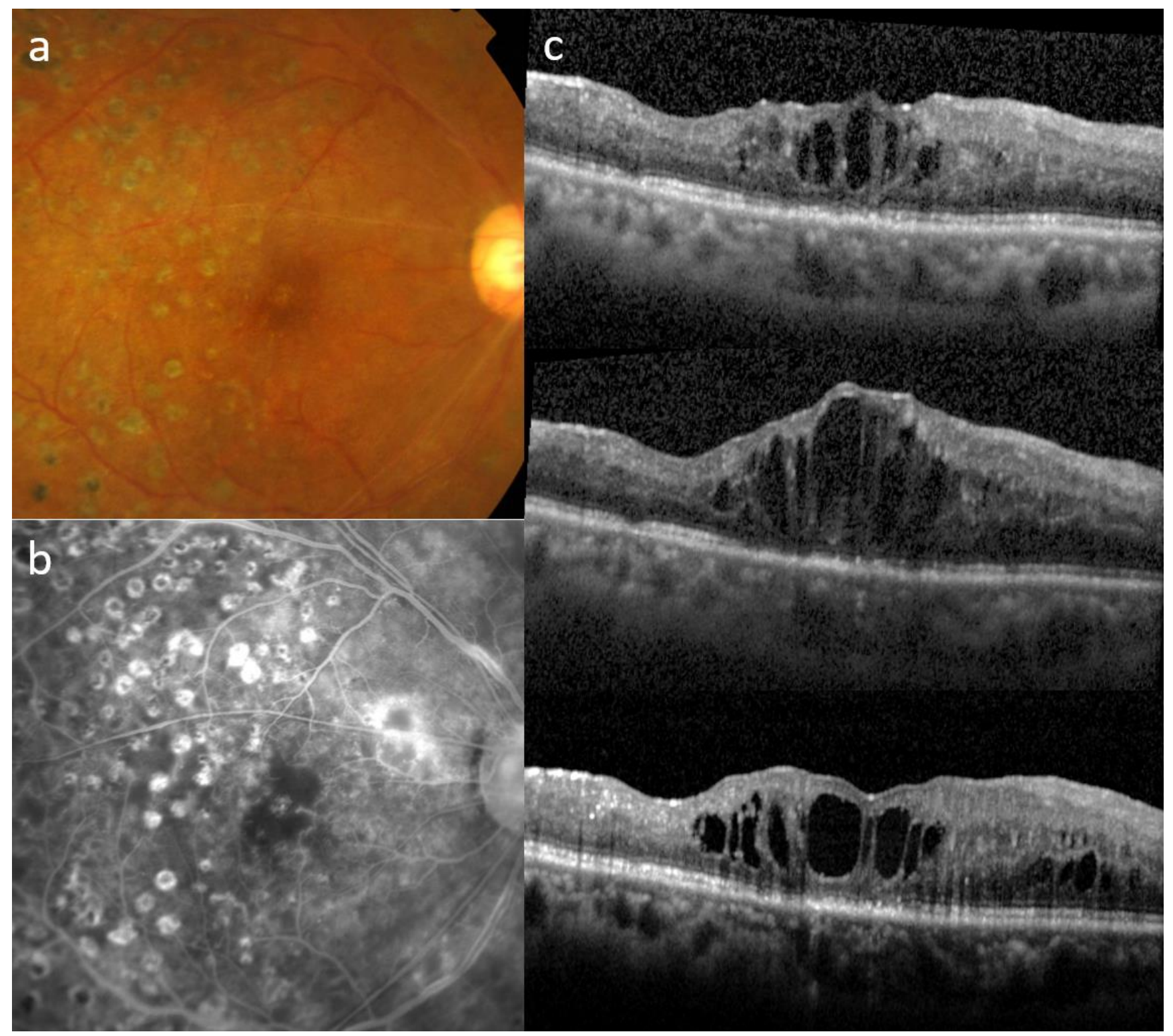

a) Fundus color photograph; b) FA; c) horizontal line of OCT baseline (top), 3 months after SRT (middle) and 6 months after SRT (bottom). Totally 51 spots with energy range from 84 to $12 \mu \mathrm{J}$ were irradiated. CMT was $372 \mu \mathrm{m}$ at baseline, increasing to $585 \mu \mathrm{m}$ at 3 months follow-up and $415 \mu \mathrm{m}$ at 6 months follow-up of SRT. 
Fig.3 SRT irradiation energy and optoacoustic values.

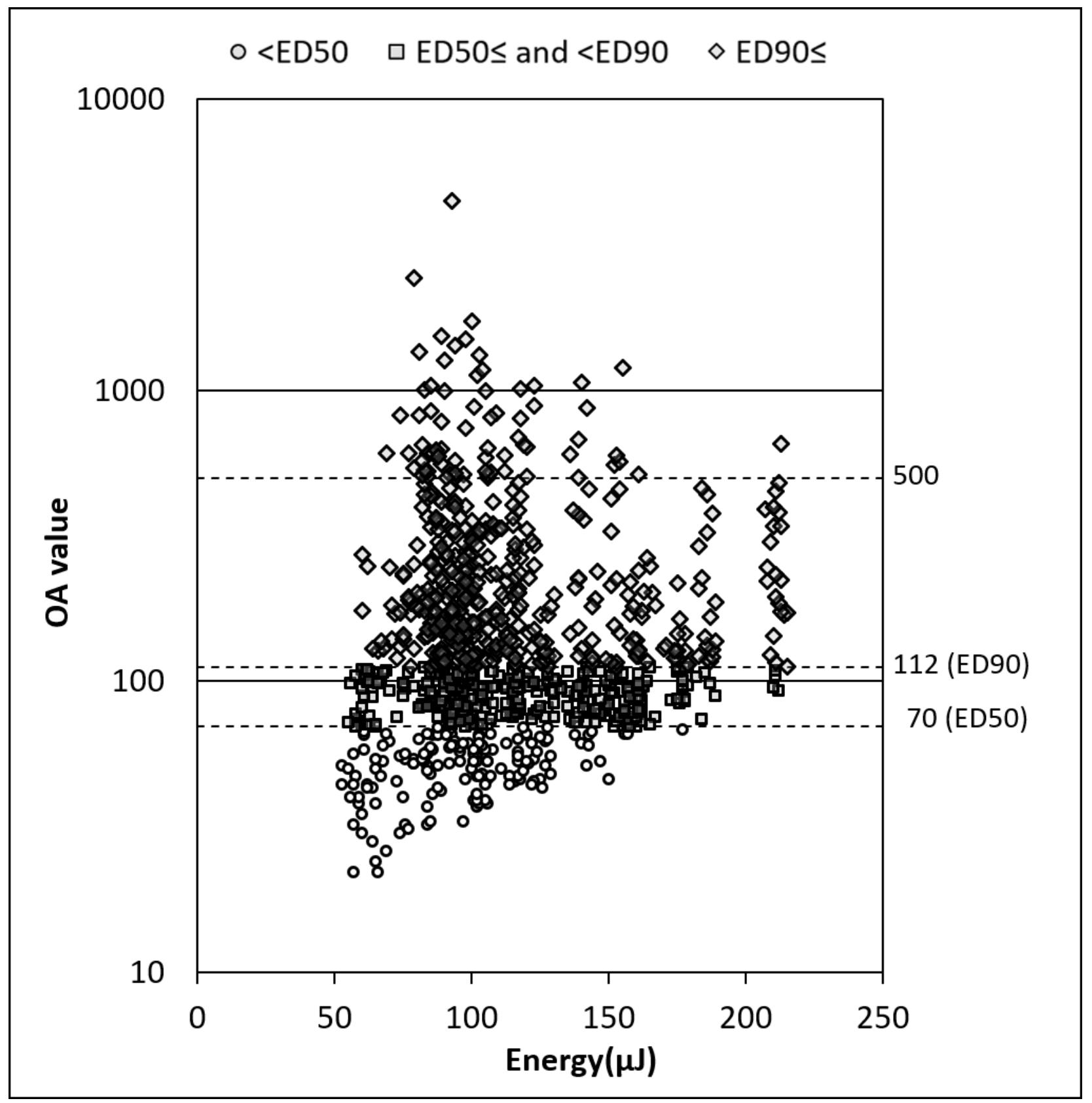

The scatter plot shows the correspondence between irradiation energy and optoacoustic value at each irradiation spot in all cases. 
Fig.4 Time course of changes in BCVA, CMT and dye leakage on FA.

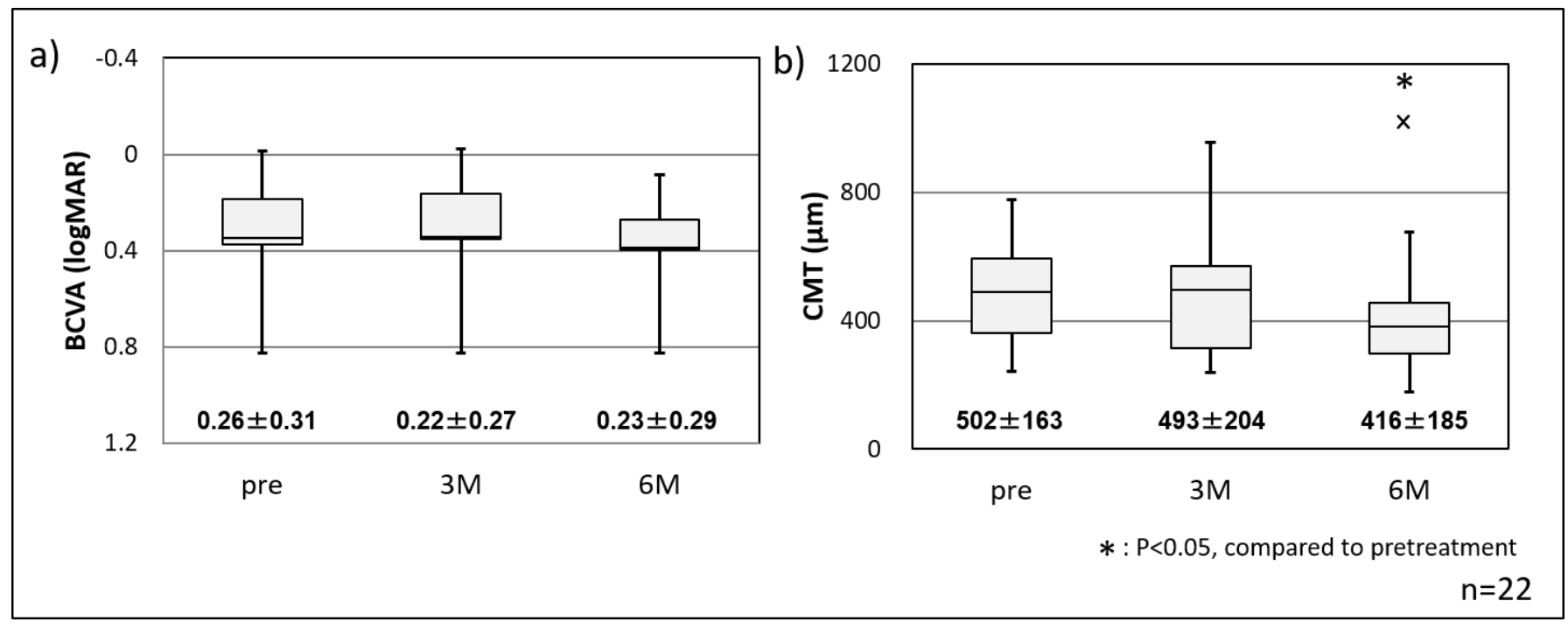

a) Boxplots showing BCVA (logMAR) before, 3 months (3M) and 6 months (6M) after SRT: The mean \pm SD of BCVA was $0.26 \pm 0.31,0.22 \pm 0.27$, and $0.23 \pm 0.29$, at baseline, $3 \mathrm{M}$, and $6 \mathrm{M}$, respectively, where there were no significant differences among different points in time. b) Boxplots showing CMT before, 3 and 6 months after SRT: The mean \pm SD of CMT was $502 \pm 163 \mu \mathrm{m}, 493 \pm$ $204 \mu \mathrm{m}, 416 \pm 185 \mu \mathrm{m}$ at baseline, 3 months, and 6 months, respectively, where a significant difference was shown between baseline and 6 months $\left({ }^{*} p<0.05\right)$. 
Fig.5 Time course of individual changes in BCVA, CMT and leakage in FA.

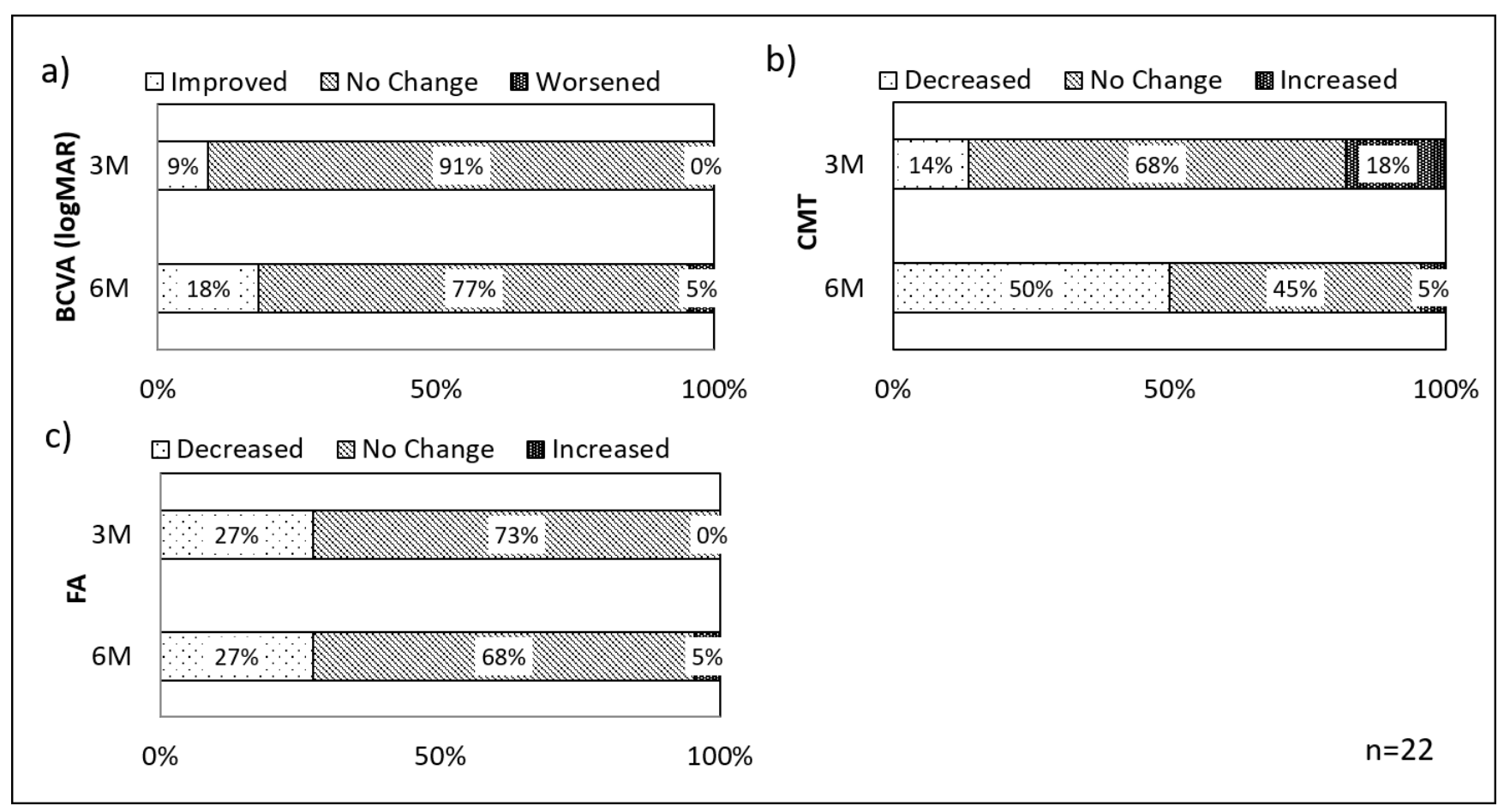

a) Proportions of patients whose BCVA was improved, unchanged or worsened by $\geq 0.2$ from baseline at $3 \mathrm{M}$ and $6 \mathrm{M}$ after treatment. The proportion of patients with improved BCVA was increased over time ( $9 \%$ at $3 \mathrm{M}$ to $18 \%$ at $6 \mathrm{M})$. b) Proportion of patients whose CMT reduced ("improve"), unchanged, or increased ("worse") by $\geq 15 \%$ from baseline at $3 \mathrm{M}$ and $6 \mathrm{M}$ after treatment. The number of the patients with reduced CMT increased (from $14 \%$ to $50 \%$ ) from $3 \mathrm{M}$ to 6M. c) Proportion of patients whose changes in dye leakage was decrease, unchanged, or increased on FA. There was almost no difference in the leakage on FA between $3 \mathrm{M}$ and 6M. 